DOI: $\underline{\text { https://doi.org/10.24867/12FA01Zivanovic }}$

\title{
ANTI PANDEMIJSKI HABITAT
}

\section{ANTI PANDEMIC HABITAT}

\author{
Nikola Živanović, Fakultet Tehničkih Nauka, Novi Sad
}

\section{Oblast - ARHITEKTONSKO PROJEKTOVANJE}

Kratak sadržaj - Ovaj istraživački rad ima za cilj prikazivanje mogućnosti projektovanja svakidašnjih arhitektonskih programa $u$ vanrednim situacijama i prilagođavanje korisnika na nove uslove života.

Ključne reči: Pandemija, Habitat, Stanovanje, Uslužne delatnosti, Objekti kulture, Promenada, Staklena bašt

\begin{abstract}
This research work primarily aims at presenting new ways of designing usual architecture during pandemic circumstances. Thus, modifying everyday life according to new rules of living.
\end{abstract}

Keywords: Pandemic, Habitat, Housing, Cettering, Culture, Glass House

\section{UVOD}

Sama organizacija života u vanrednim uslovima je nešto na šta nismo navikli, nešto što se dešava iznenada i nešto što nas kao društvo i civilizaciju zatiče iz jednog kriznog $u$ drugi krizni period nespremne u vidu organizacije, vršenja ključnih potreba pojedinaca za opstanak i toga da pojavom različitih epidemija i pandemija norme društva $u$ socijalnom i materijalnom i svakom drugom smisli menjaju u veoma kratkom vremenskom periodu. Potrebno je promeniti funkcionalne celine objekata, način ostvarivanja arhitektonskih programa kao i ostvariti potrebne higijenske uslove da bi novi način postojanja zadovoljio stare navike i učinio prelaz u novu normu življenja podnošljivijim za pojedince omogućivši korišćenje poznatih navika u uslovima evoluiranja ljudske rase. Ovaj projekat se može posmatrati kao neka vrsta modula izolovane gradnje u pandemijskim uslovima jer svojom strukturom trpi promenu svojih funkcija i samim nastavljanjem, nizanjem, ovih struktura moguće je ostvariti stvaranje naselja. Razdvajanjem namena i ostvarivanjem dovoljnog broja slobodnih površina stvara se prostor koji je moguće koristiti u vanrednim uslovima na način koji je prihvatljiv i van takvih dešavanja.

\subsection{Uzrok potrebe za projektom}

Pojam pandemije je opšte poznat, a ona zapravo predstavlja zarazu koja se u toj meri raširila da je obuhvatila više naroda i populacija, ona nastaje od epidemije koja je vezana za granice jedne države, a kada zaraza pređe granice te države postaje pandemija i tada počinje zajednička borba za iskorenjavanje problema koji je

\section{NAPOMENA:}

Ovaj rad proistekao je iz master rada čiji mentor je bila prof. dr Jelena Atanacković Jeličić. pogodio veliki broj ljudi i uticao na živote mnogih. Do ovakvih dešavanja ne dolazi toliko često, što je dobra stvar, ali ljudska rasa sporo uči i retko to radimo na svojim, a još ređe na greškama naših predaka. Upravo zato dolazi do toga da nismo spremni kada se dogodi epidemija svetskih razmera i uvek se ponašamo izgubljeno i iznenađeno, kao da takvi događaji ne mogu da se dogode nama i ako nam istorija pokazuje drugačije. Razlog širenja zaraznih virusa je jasan, povećanjem broja stanovništva u naseljima smanjuju se higijenski uslovi i kvalitet života opšte populacije postaje niži, a higijenski standardi u multimilionskim gradovima skoro nepostojeći, što direktno dovodi do pojave novih vrsta virusa, bolesti i zaraza, koje se svojim tokom neke manje, a neke više i brže šire i izazivaju opštu pometnju u zdravstvenom sistemu jedne države, a onog momenta kada ta država ne može da podnese količinu obolelih i da kontroliše njihovo kretanje i načine širenja zaraznih bolesti dolazi do pojave pandemije.

\subsection{Predlozi projekata}

Promenom klimatskih uslova, prenaseljenošću i manjkom resursa, polako dovodimo izvore našeg života i civilizacije do ivica postojanja, što dovodi do ideje da potrebna promena dizajna prostora, izrada alternativnih rešenja koja bi pomogla očuvanje ljudske rase u najgorim situacijama. Ovaj projekat predstavlja jedan vid post apokaliptične arhitekture jer svojim načinom funkcionisanja korisnika postavlja u svet koji je dovoljno izmenjen na ono na šta je pojedinac navikao i svojim predlozima korišćenja objekata daje naznake mogućeg utopijskog rešenja problema smanjenja broja populacije usled zarazne bolesti, što u određenoj meri predstavlja neku vrstu „sudnjeg dana“, apokalipse.

Iako ona nije u vidu masivnih razaranja resursa i površine planete kakvu znamo, opet predstavlja koban faktor za stanovništvo kom je potrebna nova arhitektura koja će ih zaštiti od onoga što je možda neizbežno. Istraživanja na temu drugačijih vrsta ljudskih naseobina nisu nov pojam, šezdesetih godina prošlog veka NASA je vršila ispitivanja u okviru programa nazvanog „Sealab“ (Morska laboratorija), u kom su formirali tri podvodna habitata koji su postojali kao takvi duži vremenski period i u kojima su ispitanici živeli i radili.

Svima su poznata istraživanja života na Marsu ili Mesecu, kao mogućim destinacijama na kojima bi ljudska rasa mogla da se naseli i proširi, kao potencijalnim lokacijama u slučaju potrebe za opstankom na mestu koje nije čak ni planeta na kojoj smo. Napredovanjem tehnologije i rastom finansijske moći istraživanja na ovu temu traju već duže od šest decenija. 


\section{KONCEPT PREDMETNOG PROJEKTA}

Izborom pozicije ovog idejnog rešenja kompleksa nametnut je jedan od dva tipa obalnih struktura, one koje su na samoj vodi i one koje se pruzžaju duž obale. S obzirom da je izabrano da se kompleks nalazi na obali potrebnom neophodno je smisliti šetalište i urediti priobalje. Ideja je da se projekat podeli na četiri nivoa.

Prvi nivo je šetalište koje se spušta na peščanu, Oficirsku plažu koja je produžena u skladu sa položajem i razvijanjem kompleksa, a koje bi u isto vreme služilo kao veza sa objektom i predstavljalo svojevrsan galerijski „hodnik“" na otvorenom.

Drugi nivo bi bila galerija kojoj nije moguć pristup sem posmatranje eksponata spolja, ona bi bila neka vrsta izloga gde posetioci ne bi morali da rizikuju svoje zdravlje ulaskom u sam objekat kulture.

Ovaj nivo kao i prethodni, a takođe i naredni nivoi bi u slučaju proširenja kompleksa bi li nastavljani svojom namenom sem na trećem nivou koji bi namenu menjao.

Treći nivo je nivo uslužnih delatnosti, u modularnom delu restoran, u ovom programima bi bilo obezbeđeno distanciranje posetilaca i dezinfekcioni uslovi beskontakne usluge i održavanja.

Četvrti nivo koji čini jednu celinu, a ima dve namene su prostori za stanovanje koji se kao i prva dva nivoa nastavljaju u istoj formi u slučaju proširenja kompleksa.

Način na koji stanovanje ima dve funkcije postiže se u dva nivoa, gde bi se prvi novi koristio kao prostor za život, a drugi nivo kao zastakljena bašta.

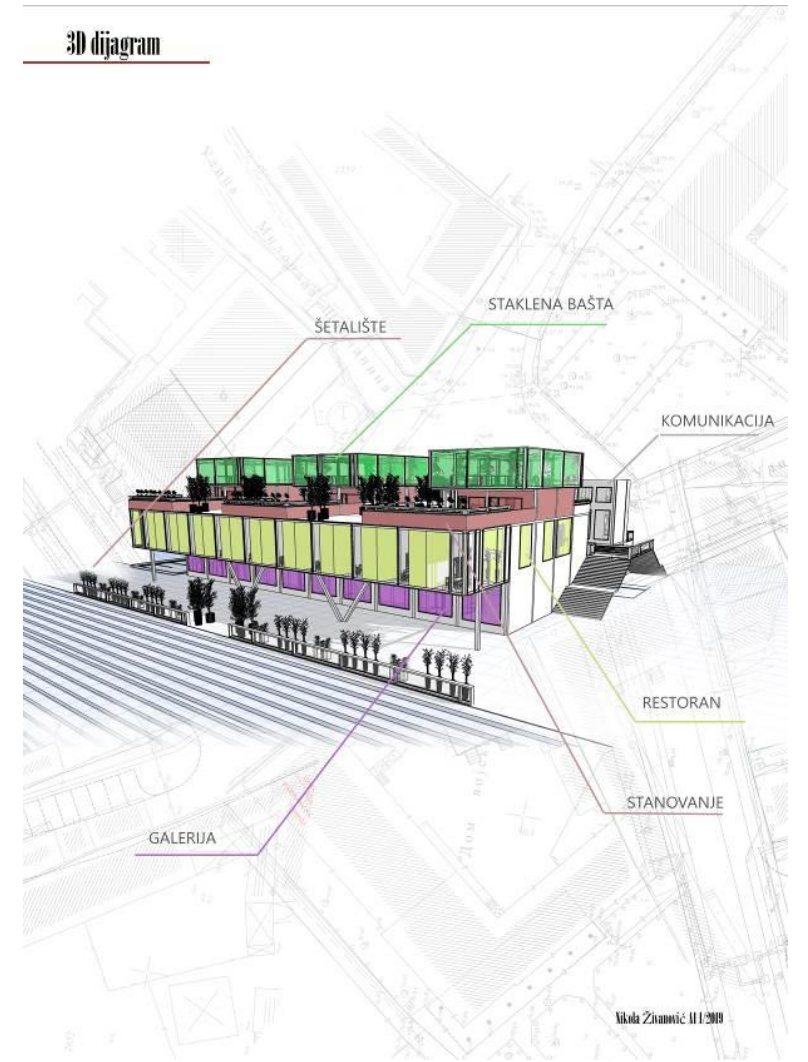

Slika 1. Dijagram prostora

\section{URBANISTIČKO REŠENJE PARCELE}

Pozicija lokacije kompleksa je u Petrovaradinu (Novi Sad), oivičena sa severne strane rekom Dunav, sa južne strane ulicom Reljkovićeva, na istočnom delu je rukavac reke Dunav, na istoku je Žeželjev most i Oficirska plaža. Pristup parceli bi se vršio izradom isključenja iz ulice Reljkovićeva na mestu gde ulica ima poluskretanje ka Žeželjevom mostu. Izradom ovog isključenja bilo bi neophodno izraditi projekat saobraćajnice koja bi pratila trenutno postojeći neplanski put, a svojim tokom prelazila rukavac reke Dunav, na kom bi bilo potrebno predvideti kolsko pešački most. Ceo kompleks bi imao kružno kretanje, od pomenute ideje za ulaz u kompleks preko novog mosta, duž kompleksa uz izlaz na Žeželjev most pored Oficirske plaže gde bi se uradila mostovska petlja za priključenje na sam most.

Urbanističkim predlogom bi moglo proširenjem kompleksa da se od ovog dela priobalja napravi izolovano ostrvo, produžavanjem rukavca reke stvorilo bi se zapravo poluostrvo, mostovski povezano sa ostatkom kopna, što bi još više uticalo na sigurnost i higijensku odvojenost i izolaciju celine. Ređanjem modularnih jedinica projekta jedne uz drugu bi se formirala saobraćajnica koja bi imala dužinu i oblik koji odgovara količini dodatih modula na početni projektovani, što bi uticalo na gustinu naseljenosti, ali ne i na bezbednost stanara, korisnika, prostora. Saobraćajnice bi bile kolske i pešačke, a bez obzira na razvoj i broj modularnih jedinica, šetalište bi se predvidelo celom dužinom prostora.

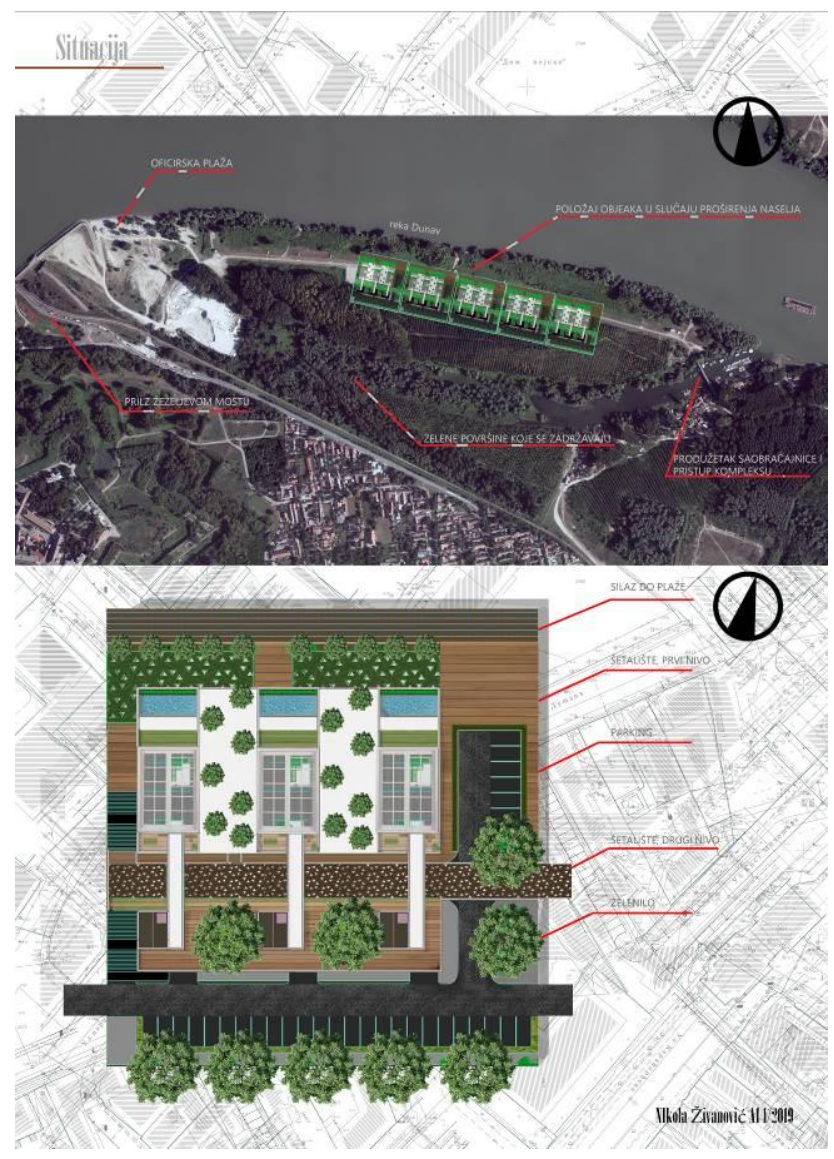

Slika 2. Situacioni prikaz parcele 


\section{ARHITEKTONSKI PROGRAMI PROJEKTA}

\subsection{Analiza promenade u okviru projekta}

Rešenje promenade kompleksa zamišljeno je kao kombinacija stepeništa, rampi i ravnih površina koje prate obalu reke i odstupaju od prave linije kako je to zahtevano od terena, a zanimljivost samom iskustvu boravka u ovom prostoru daju namene ostalih nivoa i način na koji su delovi objekta prepušteni odnosno uvučeni u odnosu na liniju obale.

\subsection{Analiza objekta kulture u okviru projekta}

Zamišljen kao izložbeni prostor slika, prostornih kompozicija, vizuelne umetnosti, nivo 2 je galerijski izložbeni prostor kom je posetiocima omogućen pristup samo sa spoljašnje strane, odnosno dela promenade do obale. $\mathrm{Na}$ ovaj način prostor šetališta omogućava dovoljan prostor između posmatrača, kontakt sa izloženim delima nije moguć, a cirkulacija vazduha je konstantno obezbeđena.

Visinski kapacitet ovih prostora je pet metara, što ga čini optimalnim prostorom za izlaganje umetničkih dela i kompozicija malih i srednjih razmera.

\subsection{Analiza gostionice u okviru projekta}

Restoran zamišljen za ovaj kompleks sastoji se od gostionice koja je na trećem nivou kompleksa, magacina koji je na nultom nivou i međunivoa, polusprata koji služi za mehanizaciju koja se koristi u funkcionisanju ideje restorana.

Namera je da se stvori prostor koji bi se koristio za obedovanje tako da parovi ili porodice koje pristupaju prostoru budu izložene brzoj dezinfekciji kroz jedan vid komore ili vetrobrana i da nakon toga budu upućeni do svojih unapred rezervisanih stolova.

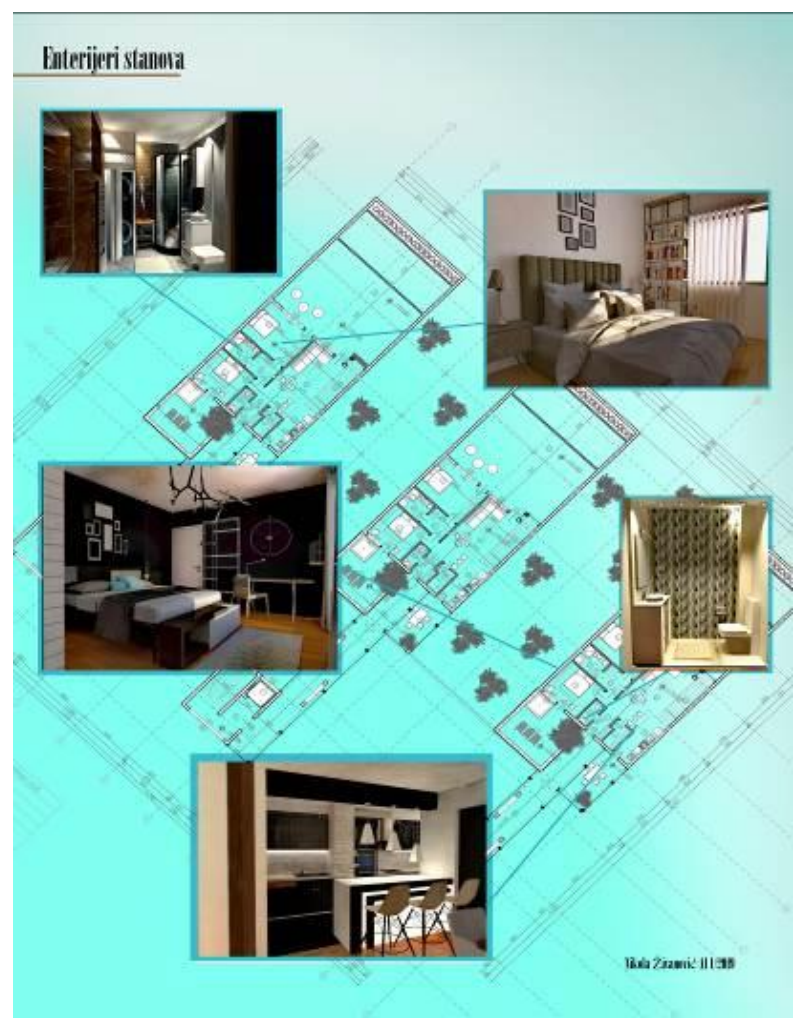

Slika 3. Prikaz enterijera kompleksa

\subsection{Analiza stanovanja u okviru projekta}

Poslednji nivo objekta namenjen je jednoporodičnom stanovanju koji sadrži staklenu baštu na drugoj etaži. Prostor je koncipiran kao stambena jedinica za maksimalno pet pojedinaca. Prostorije koje stambena jedinica sadrži su uobičajene i nije bilo potrebe da se uvode posebne mere zaštite $u$ okviru samog funkcionisanja privatnog prostora.

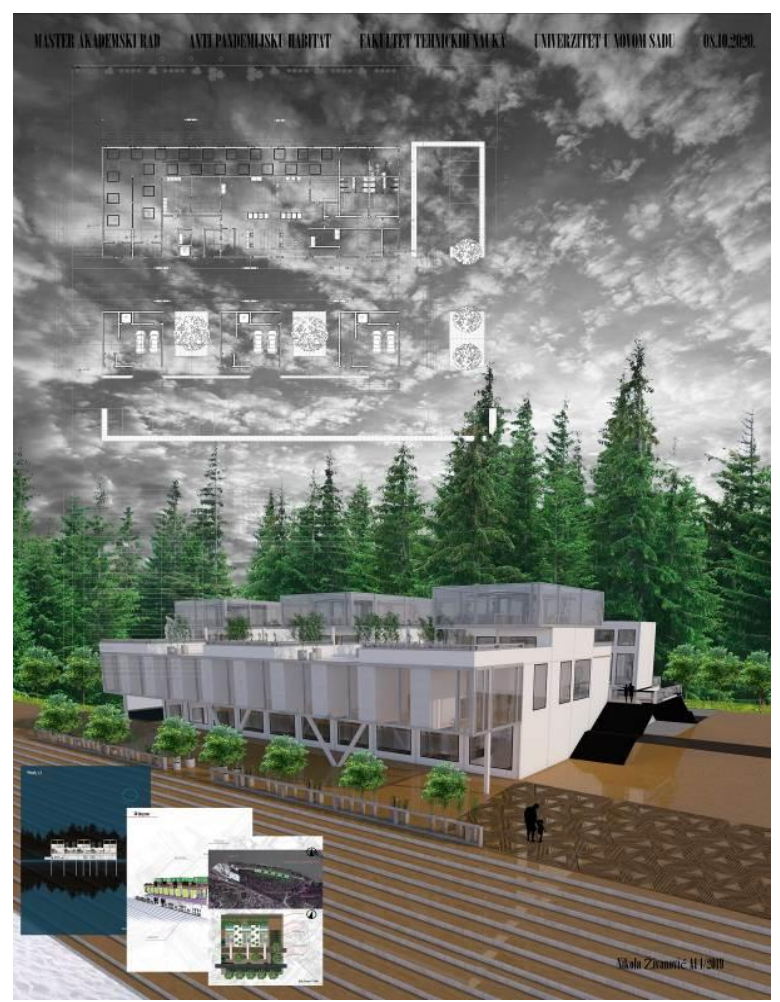

Slika 4. Sintezni prikaz kompleksa

\section{ZAKLJUČAK}

Projekat je započet nošenem idejom sigurnosti u vremenu koje je karakteristično za ljudski rod, učenje, odnosno zaboravljanje loših događaja i činjenice da se istorija, a tako i pandemije, ponavljaju i da smo svaki put zatečeni onim što nam se dešava. Tako je ideja za prostor koji bi obezbedio oređenu vrstu sigurnosti, ne pri apokalipsi u smislu razaranja infrastrukture planete $i$ invazije drugih vrsta, nego virusom, nastala.

Projektom i istraživanjem je pokazano kako je moguće neke od svakodnevnih aktivnosti i arhitektonskih programa prilagoditi novoj normi, a verujem da bi se na sličan način i razradom ideja moglo doći do rešenja za izmenu velikog broja tipologija $i$ funkcija $u$ skladu sa novonastalim uslovima.

Ključni problem projekta je bio rešavanje funkcija programa na drugačiji i bezbedniji način i dovođenje razmišljanja pri projektovanju u neke nove ravni promišljanja prostora. Kombinovanjem različitih namena u jednu megastrukturu koju je moguće nastavljati ukoliko postoji potreba za tim, stvorena je neka vrsta modularne jedinice na više nivoa koji se prepliću, a ne ugrožavaju jedan drugi, tako da je moguće postojanje većeg broja korisnika u sitom prostoru, ali zahvaljujući nivoima, na dovoljnoj udaljenosti koja obezeđuje individualnu sigurnost. 
Sam prostor može delovati veoma atraktivno za korišćenje i razvijanje u situacijama kada se ne koristi u pandemijske potrebe $\mathrm{s}$ obzirom na postojanje šetališta i prisustva vodene površine uz kompleks. Mogućnosti ovakvih projekata su beskrajne i trebalo bi ih više istraživati i možda uvesti novu tipologiju u učenje mladih projektanata u slučaju da za ovakvim objektima i njihovom realizacijom zapravo bude potrebe.

\section{LITERATURA}

[1] https://a3.geosrbija.rs/

[2] Ernst Nojfert, 2002, Arhitektonsko projektovanje 37 izdanje, Beograd, Građevinska knjiga
[3] https://mars.nasa.gov/science/goals/\#goal-4

[4] https://www.who.int

\section{Kratka biografija:}

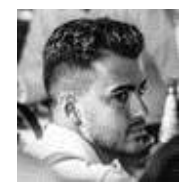

Nikola Živanović rođen je u Šapcu 1995. godine. Master rad na Fakultetu tehničkih nauka iz oblasti Arhitektura i Urbanizam, Dizajn Enterijera, Arhitektonsko Projektovanje odbranio je 2020.god. kontakt: ni6ko6la6@gmail.com 